\title{
An Algorithm for Corn Nitrogen Recommendations Using a Chlorophyll Meter Based Sufficiency Index
}

\author{
G. E. Varvel,* W. W. Wilhelm, J. F. Shanahan, and J. S. Schepers
}

\begin{abstract}
Nitrogen fertilizer continues to be the major input influencing corn (Zea mays L.) yield in the Midwest. Improved $\mathbf{N}$ recommendations should result in greater $\mathbf{N}$ use efficiency and producer profit while reducing surface and groundwater contamination. This study was conducted to develop a plant-based technique to detect and correct $\mathbf{N}$ deficiencies during the season. Chlorophyll meter readings and grain yield were collected from corn in irrigated monoculture corn and soybean [Glycine $\max (\mathrm{L}$.) Merr.]-corn cropping systems with four hybrids and five $\mathbf{N}$ fertilizer application rates in the Platte Valley near Shelton, NE. Normalized chlorophyll meter readings (sufficiency index, SI) were calculated from data collected at three vegetative stages, defined by thermal time accumulation after planting, during each of the $10 \mathrm{yr}$ of study (1995-2004). Highly significant linear correlations between SI and relative yield (normalized yield) indicated both responded similarly to $\mathbf{N}$ fertilizer application. Relationships between $\mathrm{N}$ rate and SI (at each of the three vegetative stages and combined over stages) were described by quadratic models. The combined model $\left[\left(\mathrm{SI}=0.8073+0.002(\mathrm{~N}\right.\right.$ rate $)-0.0000056(\mathrm{~N} \text { rate })^{2}, R^{2}=$ 0.70)] can be used to compute $N$ needed to achieve maximum yield. Our procedure gives producers the tools to determine if $\mathbf{N}$ is needed, and if so, the amount of $\mathrm{N}$ required for maximum yield. In addition if SI is computed for specific areas of the field, $N$ applications can be tailored to those areas, thereby reducing the potential of introducing more $\mathrm{N}$ into the system than needed to achieve maximum yield, with spatial and temporal constraints.
\end{abstract}

$\mathrm{N}$ ITROGEN fertilizer recommendations for corn in the Midwest historically have been centered on yieldbased algorithms. Mulvaney et al. (2006) describe how these yield-based systems were developed and explain many of the assumptions including the widely used mass balance approach. Work by Stanford (1973), Meisinger (1984), and Meisinger et al. (1992) indicates that when yield-based systems are used, a constant $\mathrm{N}$-use efficiency is assumed whether $\mathrm{N}$ is taken up from the soil or fertilizer. This assumption becomes somewhat questionable when results like those published by Fox and Piekielek (1995) are examined. Fox and Piekielek (1995) in fact found significant differences in apparent N-use efficiencies on nonfertilized control plots between years with low or high average yields.

The differences in N-use efficiency, depending on crop yield identified above, demonstrate not only some of the problems in developing $\mathrm{N}$ recommendations for corn but also the complex interactions among the various factors

USDA-Agricultural Research Service and Dep. of Agronomy, Univ. of Nebraska, Lincoln, NE 68583. Joint contribution of USDA-ARS and the Nebraska Agric. Res. Div. Received 5 July 2006. *Corresponding author (gvarvel1@unl.edu).

Published in Agron. J. 99:701-706 (2007).

Nitrogen Management

doi:10.2134/agronj2006.0190

(c) American Society of Agronomy

677 S. Segoe Rd., Madison, WI 53711 USA

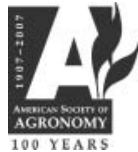

to be considered. Stanford (1982) and Keeney (1982) provide excellent reviews of techniques for creating $\mathrm{N}$ recommendations based on laboratory incubations to estimate plant available $\mathrm{N}$ mineralized from organic matter and preplant soil tests to determine inorganic nitrate $\mathrm{N}$. Laboratory incubation methods, inorganic nitrate $\mathrm{N}$ soil tests, and other procedures and techniques to determine $\mathrm{N}$ availability from other sources required to understand $\mathrm{N}$ management for crops are presented in a book edited by Hauck (1984). Chapters in the book present and discuss factors from $\mathrm{N}$ cycling in soil processes to $\mathrm{N}$ uptake by the crop affecting N-use efficiency in crop production. This book is just one example of the tremendous past effort by researchers to investigate, describe, and quantify $\mathrm{N}$ cycling processes to determine $\mathrm{N}$ available for crop production, this effort continues today.

In addition to the techniques described above, recent technological developments including global positioning systems, in-season real-time crop sensors, variable rate $\mathrm{N}$ applicators, and geographical information systems to analyze large amounts of data have improved our $\mathrm{N}$ recommendations. These developments continue to drive the expectation for further improvements in $\mathrm{N}$ management resulting in greater $\mathrm{N}$ application and use efficiency and producer profit while reducing surface and groundwater contamination.

In earlier reports, Varvel et al. (1997a, 1997b) demonstrated that chlorophyll meters provided excellent indications of in-season $\mathrm{N}$ status of several corn hybrids in both monoculture corn and soybean-corn cropping systems. In their reports, chlorophyll meter measurements taken throughout the growing season over several years indicated these data might have additional applications; including determination if and how much additional $\mathrm{N}$ fertilizer is needed for maximum yield. Therefore, our objective was to develop a plant-based technique to detect and correct $\mathrm{N}$ deficiencies during the cropping season with the ultimate purpose of improving $\mathrm{N}$-use efficiency, maintaining or improving yield, reducing $\mathrm{N}$ fertilizer costs, and reducing environmental impacts of corn production.

\section{MATERIALS AND METHODS}

A study comparing irrigated monoculture corn and soybean-corn cropping systems was initiated in 1991 on a uniform site in the Platte Valley near Shelton, NE, on a Hord silt loam (fine-silty, mixed, mesic, Pachic Haplustoll). Data for this paper are from this site for the 10-yr period of 1995 to 2004.

Before initiation of the study, the site had been in a monoculture corn production system for more than $10 \mathrm{yr}$. At the beginning of the study, corn stalks from the previous growing season were shredded and the entire area was disked twice

Abbreviations: GDD, growing degree days; SI, sufficiency index. 
before planting. Similarly, each year following, corn stalks from both cropping systems were shredded and the entire area, including that which had been in soybean, was disked twice before planting.

A split-split-split plot treatment design within a randomized complete block experiment with four replications was used. Cropping systems were assigned as the main plots, corn hybrids as the subplots, and $\mathrm{N}$ fertilizer regimes as the subsubplots. All phases of the monoculture corn and soybeancorn systems appeared each year starting with the 1991 growing season. Four Pioneer ${ }^{1}$ brand corn hybrids (3162, 3379, 3394, and 3417) differing in yield potential and maturity were selected and used in both the monoculture and rotation systems from 1991 through 2000. In subsequent years, new corn hybrids with similar growth characteristics and maturity groups were selected to replace the four original hybrids. For 2001 and 2002 they were Pioneer brand hybrids (32R42, 33B50, 33G26, and 33P66) and for 2003 and 2004 they were Pioneer brand hybrids (31N27, 33B50, 33V15, and 33P66). All corn hybrids were planted between late April and mid-May in 8-row (91-cm row spacing) by $15.2-\mathrm{m}$ long plots at approximately 74000 seeds $\mathrm{ha}^{-1}$. Soybean in the soybean-corn rotation was planted in early to mid-May. Except for $\mathrm{N}$ fertilizer application rates, both corn and soybean were produced using production practices typical to the area.

Nitrogen fertilizer as $\mathrm{NH}_{4} \mathrm{NO}_{3}$ was broadcast and immediately incorporated with a 6- to 7-mm sprinkler irrigation in early June when corn was at approximately V2 or V3 growth stages (Ritchie et al., 1986). Six fertilizer $\mathrm{N}$ regimes including five fixed $\mathrm{N}$ fertilizer rates $\left(0,50,100,150\right.$, and $\left.200 \mathrm{~kg} \mathrm{~N}^{-1}\right)$ and one "as needed" rate (Varvel et al., 1997a) were used on both crops. Only data from the fixed rate treatments were used for this analysis. Irrigation was provided as needed with a linear-drive sprinkler system.

In-season corn $\mathrm{N}$ status was monitored in both cropping systems using Minolta SPAD 502 chlorophyll meters (Peterson et al., 1993) starting at the V8 growth stage and continuing through R2 (Ritchie et al., 1986). Chlorophyll meter readings were taken from the uppermost fully expanded leaf (collar visible) until the VT growth stage. After VT, meter readings were collected from the ear leaf. All measurements were taken on 30 randomly selected plants within each plot using the procedure described by Blackmer et al. (1993).

Chlorophyll meter readings were analyzed by sampling date each year. As noted in earlier publications (Varvel et al., 1997a, 1997b), chlorophyll meter readings and grain yields responded similarly to $\mathrm{N}$ fertilizer applications and chlorophyll meter readings were an excellent indication of $\mathrm{N}$ sufficiency or deficiency in irrigated corn. Actual SPAD readings were normalized to adjust for variation not associated with $\mathrm{N}$ nutrition. The SPAD readings from all treatments were divided by the maximum reading from all $\mathrm{N}$ rates within that cropping system, hybrid, and replication within each date and year to obtain a sufficiency index (SI), which is expressed as a decimal (Peterson et al., 1993).

Chlorophyll meter data were collected at various sampling dates each year over the $10 \mathrm{yr}$ of the study. Combining the data over years required computation of thermal times (growing degree days, GDD) for each of the dates chlorophyll meter data were collected. Thermal time computations were made using Method II of McMaster and Wilhelm (1997). In Method

\footnotetext{
${ }^{1}$ Trade names and company names are included for the benefit of the reader and do not imply any endorsement or preferential treatment of the product by the authors, USDA-Agricultural Research Service, or the Agricultural Research Division of the University of Nebraska.
}

II computations, daily maximum $\left(\mathrm{T}_{\mathrm{MAX}}\right)$ and minimum $\left(\mathrm{T}_{\mathrm{MIN}}\right)$ temperatures, a base $\left(\mathrm{T}_{\mathrm{BASE}}\right)$ temperature of $10^{\circ} \mathrm{C}$, and a threshold $\left(\mathrm{T}_{\text {THRESH }}\right)$ temperature of $30^{\circ} \mathrm{C}$ are used. Then GDD $=\left[\left(\mathrm{T}_{\text {MAX }}+\mathrm{T}_{\text {MIN }}\right) / 2\right]-\mathrm{T}_{\text {BASE }}$ with the following conditions: If $\mathrm{T}_{\text {MAX }}<\mathrm{T}_{\mathrm{BASE}}$, then $\mathrm{T}_{\mathrm{MAX}}=\mathrm{T}_{\mathrm{BASE}}$, if $\mathrm{T}_{\mathrm{MIN}}<\mathrm{T}_{\mathrm{BASE}}$, then $\mathrm{T}_{\text {MIN }}=\mathrm{T}_{\text {BASE }}$, if $\mathrm{T}_{\text {MIN }}>\mathrm{T}_{\mathrm{THRESH}}$, then $\mathrm{T}_{\text {MIN }}=\mathrm{T}_{\text {THRESH }}$, and if $\mathrm{T}_{\text {MAX }}>\mathrm{T}_{\text {THRESH }}$, then $\mathrm{T}_{\mathrm{MAX}}=\mathrm{T}_{\mathrm{THRESH}}$. These substitutions are made before calculating $\left(\mathrm{T}_{\mathrm{MAX}}+\mathrm{T}_{\mathrm{MIN}}\right) / 2$.

Final grain yield was determined with a plot combine by harvesting three interior rows for the entire length of each plot. Yield data were adjusted to $155 \mathrm{~g} \mathrm{~kg}^{-1}$ moisture. Grain yield data were also normalized by dividing each yield by the maximum yield from all fixed $\mathrm{N}$ fertilizer rate treatments within that cropping system, hybrid, and replication to obtain a relative grain yield - analogous to the computation above of SI for chlorophyll meter readings.

Data from the study were analyzed both within and across cropping systems using regression analyses to determine whether responses to applied $\mathrm{N}$ fertilizer were significant. Four response models (quadratic, quadratic-plus-plateau, exponential, and square root) were fit to SI and normalized grain yield data using the NLIN procedure in SAS (Ihnen and Goodnight, 1985). All statistical analyses were performed using PC Version 9.1 of the Statistical Analyses System for Windows (SAS Institute, 2003).

\section{RESULTS AND DISCUSSION}

Corn grain yields from both the monoculture corn and soybean-corn system were collected and analyzed for this paper, but emphasis has been put on data from the monoculture corn system because it represented a wider range of $\mathrm{N}$ availability conditions. Grain yields responded similarly in both cropping systems (Varvel and Wilhelm, 2003), but response to $\mathrm{N}$ fertilizer in monoculture corn was much greater in magnitude than in the soybean-corn system. Also, for the $10 \mathrm{yr}$ of this study, hybrid differences were significant, but all hybrids responded similarly to $\mathrm{N}$ fertilizer in both cropping systems (hybrid by $\mathrm{N}$ interaction was nonsignificant). These results eliminated the need to develop response functions for each hybrid. For the remainder of the analyses, the mean response over all hybrids is described.

Corn grain yields in the monoculture corn system ranged from 3.50 to $13.63 \mathrm{Mg} \mathrm{ha}^{-1}$ during the $10 \mathrm{yr}$ of the study (Fig. 1) and significant responses to the applied N fertilizer were obtained every year. It is apparent that although maximum grain yields varied from year to year (ranging from a low of $10.44 \mathrm{Mg} \mathrm{ha}^{-1}$ in 1995 to a high of $13.63 \mathrm{Mg} \mathrm{ha}^{-1}$ in 2004), in most years maximum yield occurred between the 150 and $200 \mathrm{~kg} \mathrm{~N}^{-1}$ rate (Fig. 1). Regression analyses performed on these data, combined over years, using a quadratic response model indicated the maximum yield occurred at $174 \mathrm{~kg} \mathrm{~N}^{-1}$ for this site. For each year individually, regression analysis indicated maximum grain yield occurred within $10 \mathrm{~kg} \mathrm{~N} \mathrm{ha}^{-1}$ of the $174 \mathrm{~kg} \mathrm{~N} \mathrm{ha}^{-1}$ in all years except $1995\left(140 \mathrm{~kg} \mathrm{~N} \mathrm{ha}^{-1}\right)$ and $2004\left(200 \mathrm{~kg} \mathrm{~N} \mathrm{ha}^{-1}\right)$. This result supports conclusions from research by Blackmer et al. (1997) in Iowa, Fox and Piekielek (1995) in Pennsylvania, Kachanoski et al. (1996) in Ontario, Canada, Mulvaney et al. (2006) in Illinois, and Vanotti and Bundy (1994) in Wisconsin, that contradict the yield goal method for 


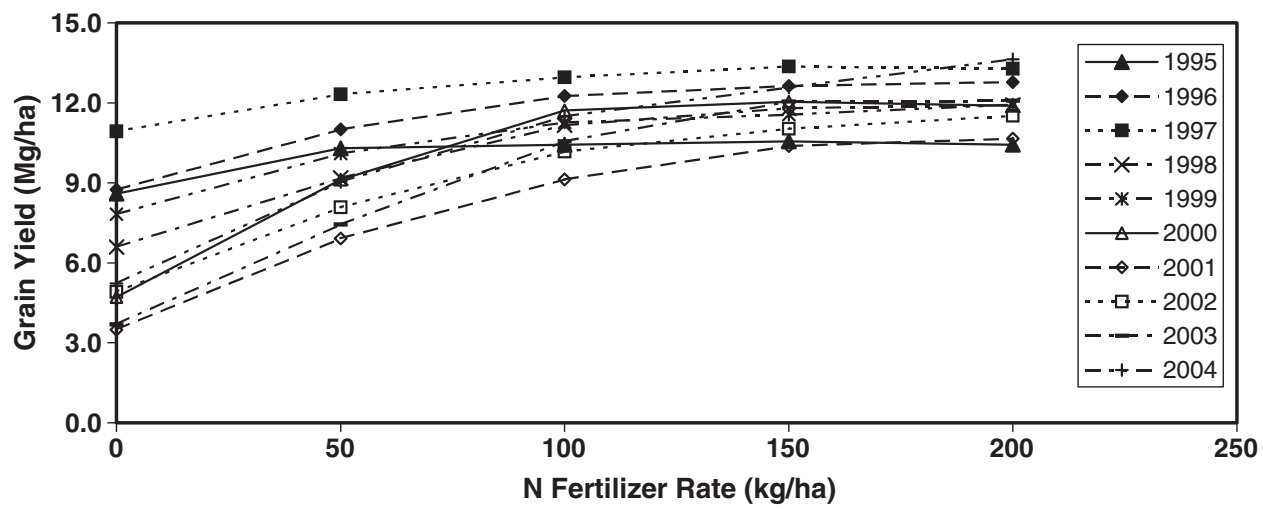

Fig. 1. Corn grain yield response to $\mathbf{N}$ fertilizer applications each year in an irrigated monoculture corn cropping system at Shelton, $\mathbf{N E}$ (1995-2004).

making $\mathrm{N}$ fertilizer recommendations for corn. This method has relied on a yield goal based system that assumes a constant factor of 19.4 to $24.2 \mathrm{~kg} \mathrm{~N} \mathrm{Mg}^{-1}$ of grain, multiplied by the expected yield goal to generate the basic $\mathrm{N}$ application recommendation (Mulvaney et al., 2006). Using this approach with actual maximum yields from each individual year for the results from our multiyear study would have produced different $\mathrm{N}$ fertilizer recommendations calculated across years ranging from a low of $203 \mathrm{~kg} \mathrm{~N} \mathrm{ha}^{-1}$ in 1995 to a high of $264 \mathrm{~kg} \mathrm{~N} \mathrm{ha}^{-1}$ in 2004 (using the more conservative $19.4 \mathrm{~kg} \mathrm{~N} \mathrm{Mg}^{-1}$ factor). Obviously if the greater factor, $24.2 \mathrm{~kg} \mathrm{~N} \mathrm{Mg}^{-1}$ grain were used, the magnitude and range of $\mathrm{N}$ fertilizer recommendations would be greater. Even if we used the average maximum yield over the 10-yr period, $12.1 \mathrm{Mg} \mathrm{ha}^{-1}$, $235 \mathrm{~kg} \mathrm{~N}$ ha $^{-1}$ would have been recommended on an annual basis. All of these recommendations are much higher than the $174 \mathrm{~kg} \mathrm{~N} \mathrm{ha}^{-1}$ indicated by solving for the maximum of the quadratic response function describing the data in Fig. 1. These results support the fact that factors other than, or in addition to, amount of available $\mathrm{N}$ determines fluctuations in maximum corn grain yields from year to year. Some of these factors are rainfall amount and seasonal distribution, soil water conditions, thermal time accumulation patterns, total incoming and intercepted radiation, dates of planting, and intensity of pests and diseases.

Our approach to solving the dilemma of predicting the amount of $\mathrm{N}$ needed to maximize yield involved use of SPAD 502 chlorophyll meters (Peterson et al., 1993) for in-season monitoring of plant $\mathrm{N}$ status. Chlorophyll meter data had been shown to be highly correlated with in-season N status of corn (Varvel et al., 1997a, 1997b), but data throughout the years were collected on calendar date (i.e., every Wednesday) and not linked to specific developmental stage for the plant. Basing the analyses on calendar day, days after planting, or days after emergence proved unsuccessful. This obstacle had to be overcome before we could test whether a modeling approach that could predict if additional $\mathrm{N}$ was needed, and how much, additional $\mathrm{N}$ would be required for maximum yield would function successfully. Our solution was to use thermal time accumulation (GDD) based on Method II of McMaster and Wilhelm (1997). This approach allowed data to be combined and compared both within and across the $10 \mathrm{yr}$ of the study.
Determination of $\mathrm{N}$ deficiencies at the earliest possible time in the growing season (earliest stage of crop development) will increase a producer's opportunity and potential ability to correct that deficiency. Chlorophyll meter data were consistently available in all years at or near 450, 560, and $670 \mathrm{GDD}$, corresponding approximately to V8, V10, and V12 growth stages (Ritchie et al., 1986), respectively. Analyses of data collected at these times from the monoculture corn system were used to determine how early in the season chlorophyll meter data could be used to predict future crop $\mathrm{N}$ need, how much $\mathrm{N}$ was needed, and if analyses based on data collected later in the season improved the accuracy of predicted $\mathrm{N}$ need.

As noted above, Varvel et al. (1997a, 1997b) demonstrated $\mathrm{N}$ fertilizer significantly increased both corn grain yield and chlorophyll meter readings in this study. Since the specific grain yield response to applied $\mathrm{N}$ varied from year to year (Fig. 1), yield data were normalized by dividing each yield by the maximum yield from all fixed $\mathrm{N}$ fertilizer rate treatments within that cropping system, hybrid, and replication to obtain a relative grain yield (Fig. 2) - analogous to the computation of SI for chlorophyll meter readings. Linear correlations between relative grain yield and SI at the three times $(450,560$, and 670 GDD) each year across the $10 \mathrm{yr}$ of the study indicated the variables were highly related and that normalized yield and SI responded similarly to $\mathrm{N}$ fertilizer (Table 1).

The task of describing the relationship between $\mathrm{N}$ rate and SI remained. The first step of this process was to select an equation of appropriate form. Using the approach described by Cerrato and Blackmer (1990), four of the response models they described (quadratic, quadratic-plus-plateau, exponential, and square root) were fit to the data using NLIN procedure in SAS (Ihnen and Goodnight, 1985). All four models had $R^{2}$ values of approximately 0.70 , similar mean square errors, and residuals that were normally distributed with a slight bias at the highest $\mathrm{N}$ fertilizer rates (data not shown). Given that chlorophyll meter-based SI values were normalized to maximum values of one, this bias was expected. Taken in total, these factors indicated all functions fit the data similarly. Our previous publications (Varvel et al., 1997a, 1997b) from this long-term study show that both yields and chlorophyll meter readings decreased slightly at $\mathrm{N}$ 


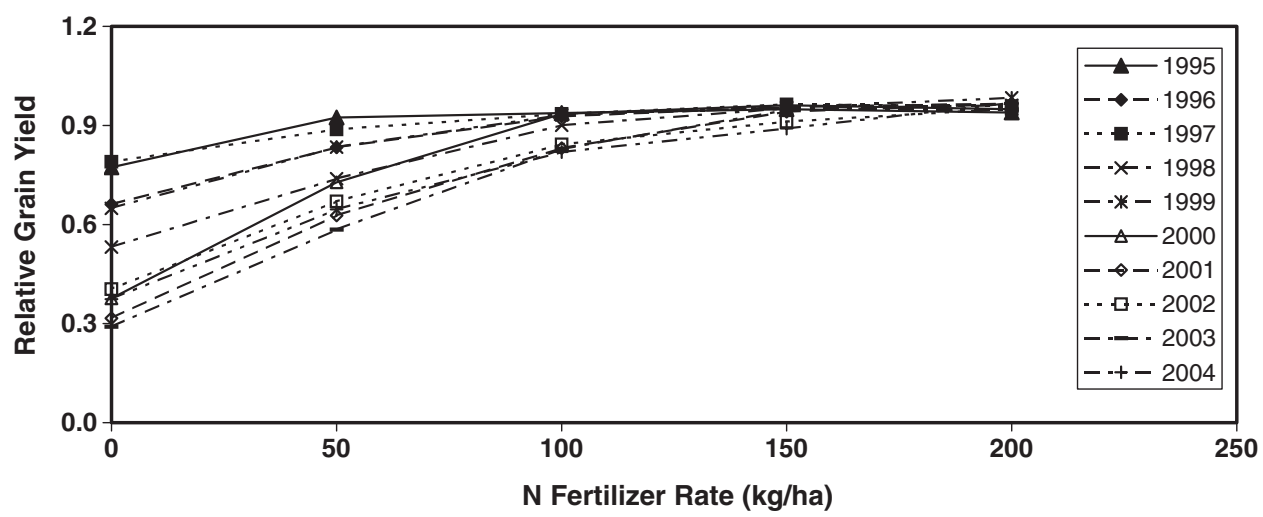

Fig. 2. Relative corn grain yield response to $\mathbf{N}$ fertilizer applications each year in an irrigated monoculture corn cropping system at Shelton, NE (1995-2004).

fertilizer rates above optimum (quadratic response). Collectively these facts support our decision to use the quadratic model to describe the relationship between $\mathrm{N}$ fertilizer rate and relative corn grain yield. In a recent publication, Miguez and Bollero (2006) also used the quadratic model in their analyses to describe the relationship between $\mathrm{N}$ fertilizer rate and corn grain yield.

Quadratic models for the three observation times (at 450, 560, and 670 GDD) had intercepts and linear and quadratic coefficients similar in magnitude (Table 2). However when compared using contrast statements in regression analyses, they were determined to be statistically different. This outcome is not surprising considering the large number of degrees of freedom in the analyses $(N=800)$. All three equations reached a maximum SI at about $170 \mathrm{~kg} \mathrm{~N} \mathrm{ha}^{-1}$, similar to the $174 \mathrm{~kg} \mathrm{ha}^{-1}$ $\mathrm{N}$ rate found from regression of $\mathrm{N}$ rate and maximum grain yield from data in Fig. 1. These results, and the relative similarity of the equations, indicated chlorophyll meter-based SI values throughout much of vegetative growth for corn were fairly stable. Based on this premise, we felt it was appropriate to combine data from all three thermal times and fit a single quadratic model to test its appropriateness for use across the vegetative phase (Table 2). As would be expected, this model was very similar to the models from the individual thermal times, with the intercept and linear and quadratic coefficients intermediate to those describing the SI response at each individual thermal time (Table 2). Again, given the exceptionally large number of degrees of freedom available $(N=2400)$, when this equation was compared to the three separate equations using an F test, it was found to be significantly different. In spite of statistical pro- cedures, the combined quadratic model appeared similar to the individual equations obtained at the three thermal times, and it seemed plausible that it could be used to represent the relationship between SI and $\mathrm{N}$ fertilizer rates throughout the vegetative growth period.

From a practical standpoint, this approach seemed worthy of consideration. Also, the optimum $\mathrm{N}$ fertilizer rate of $179 \mathrm{~kg} \mathrm{~N} \mathrm{ha}^{-1}$ for the overall model was again very close to those obtained for the individual thermal time models. Using this information, we determined the amount of $\mathrm{N}$ fertilizer that would be recommended from each of the individual thermal time equations and from the overall equation at selected SI values. This test seemed to be a practical way to determine how much variation would be obtained in the amount of $\mathrm{N}$ fertilizer recommended from the so-called "statistically different" equations. Using SI values of $0.90,0.925$, and 0.95 , the calculated amount of $\mathrm{N}$ needed from the three thermal time equations ranged from 112 to $145 \mathrm{~kg} \mathrm{~N} \mathrm{ha}^{-1}, 95$ to $122 \mathrm{~kg} \mathrm{~N}^{-1}$, and 72 to $94 \mathrm{~kg} \mathrm{~N}^{-1}$, respectively. Using these same SI values $(0.90,0.925$, and 0.95$)$, the calculated amounts of $\mathrm{N}$ needed from the overall equation were 125,105 , and $80 \mathrm{~kg} \mathrm{~N}^{-1}$, respectively. Although the values are slightly different, given the amount of natural variation in field situations, the amounts of $\mathrm{N}$ fertilizer recommended using the overall equation are representative of the range of rates recommended from the individual equations. Practically, using one equation from approximately V8 through V12 growth stages to determine potential $\mathrm{N}$ fertilizer needs is much easier to implement.

Logically, a question arises as to whether this model is specific to monoculture corn. Because the relationship is

Table 1. Linear correlation of relative corn grain yield with relative chlorophyll meter readings at different stages in an irrigated monoculture corn system for 1995 through 2004 at Shelton, NE.

\begin{tabular}{|c|c|c|c|c|c|c|c|c|c|c|c|}
\hline \multirow[b]{2}{*}{ Thermal time, GDD $\ddagger$} & \multicolumn{11}{|c|}{ Linear correlation coefficients $(r) \dagger$} \\
\hline & $1995 \S$ & 1996 & 1997 & 1998 & 1999 & 2000 & 2001 & 2002 & 2003 & 2004 & 1995-2004| \\
\hline \multicolumn{12}{|l|}{${ }^{\circ} \mathbf{C}$ day } \\
\hline 450 & 0.55 & 0.79 & 0.82 & 0.86 & 0.82 & 0.79 & 0.84 & 0.75 & 0.93 & 0.72 & 0.73 \\
\hline 560 & 0.66 & 0.85 & 0.74 & 0.92 & 0.90 & 0.88 & 0.85 & 0.75 & 0.94 & 0.79 & 0.78 \\
\hline 670 & 0.66 & 0.90 & 0.74 & 0.84 & 0.89 & 0.88 & 0.90 & 0.73 & 0.91 & 0.76 & 0.78 \\
\hline
\end{tabular}

$\dagger$ All correlations above were significant at the 0.001 probability levels.

$\$$ Thermal time (GDD) by Method II (McMaster and Wilhelm, 1997).

$\$ 80$ data points were used for each individual year and thermal time linear correlation analyses.

If 800 data points were used for the overall (1995-2004) linear correlation analyses. 
Table 2. Quadratic response models from regression analyses of relative chlorophyll meter readings (SI) and $\mathbf{N}$ fertilizer rates at three thermal times (GDD) separate and combined for (19952004) monoculture corn data at Shelton, NE.

\begin{tabular}{|c|c|c|c|}
\hline Thermal time, GDD $\dagger$ & Quadratic model & $\mathbf{N} \S$ & $R^{2} \boldsymbol{I}$ \\
\hline \multicolumn{4}{|l|}{${ }^{\circ} \mathbf{C}$ day } \\
\hline 450 & $\begin{array}{c}\text { SI }=0.8324+0.00160(\mathrm{~N} \text { rate }) \\
-0.00000417(\mathrm{~N} \text { rate })^{2}\end{array}$ & 800 & $0.64 * * *$ \\
\hline 560 & $\begin{array}{c}\mathrm{SI}=\mathbf{0 . 7 9 8 2}+\mathbf{0 . 0 0 2 1 1}(\mathrm{N} \text { rate }) \\
-\mathbf{0 . 0 0 0 0 0 5 8 5}(\mathrm{N} \text { rate })^{2}\end{array}$ & 800 & $0.75 * * *$ \\
\hline 670 & $\begin{array}{c}\mathrm{SI}=\mathbf{0 . 7 9 1 4}+\mathbf{0 . 0 0 2 3 0}(\mathrm{N} \text { rate }) \\
\quad-\mathbf{0 . 0 0 0 0 0 6 8 0}(\mathrm{N} \text { rate })^{2}\end{array}$ & 800 & $0.73 *$ \\
\hline All & $\begin{array}{c}\mathrm{SI}=\mathbf{0 . 8 0 7 3}+\mathbf{0 . 0 0 2 0 0}(\mathrm{N} \text { rate }) \\
\quad-\mathbf{0 . 0 0 0 0 0 5 6 0 ( \mathrm { N } \mathrm { rate } ) ^ { 2 }}\end{array}$ & 2400 & $0.70 * * *$ \\
\hline
\end{tabular}

$* * *$ Significant at the 0.001 probability level.

$\dagger$ Thermal time (GDD) by Method II (McMaster and Wilhelm, 1997).

$\$ \mathrm{~N}$ rate in $\mathrm{kg} \mathrm{ha}^{-1}$.

\$ Number of data points used in regression analyses.

II Regression correlation coefficient for the model.

built on in-season assessment of canopy $\mathrm{N}$ status, all sources and uses of $\mathrm{N}$ by the crop and other components of the $\mathrm{N}$ cycle are accounted for and $\mathrm{N}$ availability is "reported" by the plant. We believe the model is valid beyond its conditions of development, monoculture corn. Earlier research indicated corn following soybean at this location required less preplant fertilizer (65 $\mathrm{kg} \mathrm{N} \mathrm{ha}^{-1} \mathrm{yr}^{-1}$ less) for maximum grain yields than in the monoculture corn system (Varvel and Wilhelm, 2003). In addition, maximum grain yields were generally greater for the soybean-corn system than for the monoculture corn system (Varvel and Wilhelm, 2003). To test our supposition, SI data collected from the soybeancorn system for all three thermal times (2400 additional observations) was combined with the data from the monoculture corn system and analyzed as described above. The optimum $\mathrm{N}$ fertilizer rate for maximum SI (176 $\mathrm{kg} \mathrm{N} \mathrm{ha}{ }^{-1}$ ) was almost identical to that for the monoculture corn system, demonstrating our model's robustness and applicability in other cropping situations with varying amounts of available $\mathrm{N}$ early in the growing season. This analysis also demonstrated that even though the magnitude of $\mathrm{N}$ response was much less in the soybean-corn system, the response curves maximums were similar. Since the magnitude of response was less, it was also obvious that SI values in the soybeancorn system were much greater, indicating that less additional $\mathrm{N}$ fertilizer would need to be added for maximum grain yields. As we had postulated above, by monitoring the plant we were able to give credit for the additional $\mathrm{N}$ available to corn following soybean.

\section{CONCLUSIONS}

Analyses presented in this paper indicate chlorophyll meters can be used to determine the amount of $\mathrm{N}$ needed for maximum yields. Several researchers have demonstrated that chlorophyll meters can be used during the growing season to determine whether corn is $\mathrm{N}$ deficient (Blackmer and Schepers, 1995; Peterson et al., 1993; Varvel et al., 1997a), but few, if any, have had success quantifying the amount of $\mathrm{N}$ fertilizer needed for a single in-season application. Our results indicate this is possible for monoculture corn and soybean-corn systems, at least in environments similar to the Shelton experiment. This procedure requires areas where sufficient $\mathrm{N}$ fertilizer (beyond yield-limiting rates) has been applied so that SI values can be determined, a condition not difficult to accomplish. Once an area of well-fertilized corn (nonyield limiting) has been established, our model indicates that we can collect chlorophyll meter data anytime during vegetative growth between V8 and V12 from several areas of the field, which is then compared to data from the well-fertilized area to determine SI values. These values can then be put into the generalized model shown in Table 2 or graphically in Fig. 3 and solved for $\mathrm{N}$ rate. This $\mathrm{N}$ rate is the theoretical amount of preplant $\mathrm{N}$ fertilizer required to obtain that SI. This theoretical amount is subtracted from the optimum $\mathrm{N}$ rate $\left(179 \mathrm{~kg} \mathrm{~N} \mathrm{ha}^{-1}\right)$ to determine the amount of $\mathrm{N}$ fertilizer (Fig. 3) to be applied at or very near the time of chlorophyll meter data collection to achieve the maximum yield obtainable within the constraints of location and season.

The outlined methodology is a more proactive approach to uniform preplant $\mathrm{N}$ applications and should reduce $\mathrm{N}$ losses due to leaching or denitrification because the $\mathrm{N}$ is being applied during the period of highest demand by the corn plant. It also gives producers the option to site-specifically apply $\mathrm{N}$ fertilizer only to those areas where needed if they have equipment to variably apply N. Future plans include additional testing of the model on producer fields and other locations.

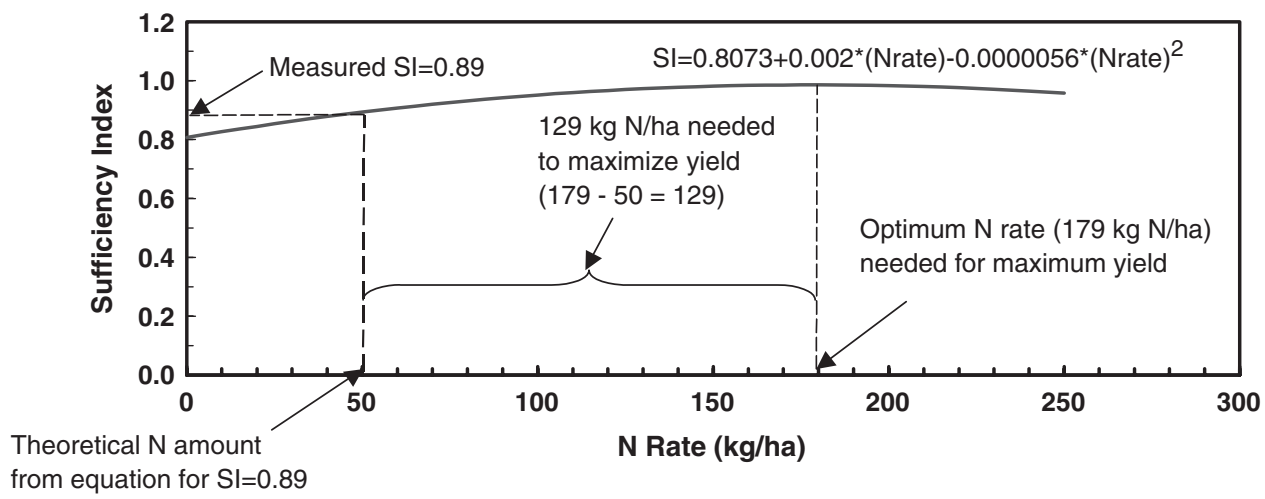

Fig. 3. Quadratic response model from regression analyses of relative chlorophyll meter readings (SI) and $\mathrm{N}$ fertilizer rates at all growth stages combined for (1995-2004) monoculture corn data at Shelton, NE, and an example of an in-season $N$ application calculation. 
This general approach should be valid regardless of the instruments used to acquire data for SI. The only requirements are that the instrument readings respond to $\mathrm{N}$ rate and they are related to yield. These limitations are quite reasonable and should allow the approach to be used with the array of on-the-go sensors under development at this time. Wide-area use of modern sensors and this method of assessing the amount of $\mathrm{N}$ needed to maximize yield will reduce application of $\mathrm{N}$ in excess of crop need while maintaining high yield levels required for profitable grain production enterprises.

\section{ACKNOWLEDGMENTS}

The authors would like to thank Lucius Reinbolt for his suggestions and contributions to the statistical approaches used in the manuscript.

\section{REFERENCES}

Blackmer, T.M., J.S. Schepers, and M.F. Vigil. 1993. Chlorophyll meter readings in corn as affected by plant spacing. Commun. Soil Sci. Plant Anal. 24:2507-2516.

Blackmer, T.M., and J.S. Schepers. 1995. Use of a chlorophyll meter to monitor $\mathrm{N}$ status and schedule fertigation for corn. J. Prod. Agric. 8:56-60.

Blackmer, A.M., R.D. Voss, and A.P. Mallarino. 1997. Nitrogen fertilizer recommendations for corn in Iowa. Pamphlet 1714. Iowa State Univ., Ames.

Cerrato, M.E., and A.M. Blackmer. 1990. Comparison of models for describing corn yield response to nitrogen fertilizer. Agron. J. 82:138-143.

Fox, R.H., and W.P. Piekielek. 1995. The relationship between corn grain yield goals and economic optimum nitrogen fertilizer rates. Agron. Ser. 136. Pennylvania State Univ., University Park.

Hauck, R.D. (ed.). 1984. Nitrogen in crop production. ASA, CSSA, and SSSA, Madison, WI.

Ihnen, L.A., and J.H. Goodnight. 1985. The NLIN procedure. p. 575606. In SAS user's guide: Statistics. SAS Inst., Cary, NC.

Kachanoski, R.G., I.P. O'Halloran, D.S. Aspinall, and P. Von Bertoldi.
1996. Delta yield: Mapping fertilizer nitrogen requirement for crops. Better Crops 80(3):20-23.

Keeney, D.R. 1982. Nitrogen-availability indices. p. 711-733. In A.L. Page et al. (ed.) Methods of soil analysis. Part 2. 2nd ed. Agron. Monogr. 9. ASA and SSSA, Madison, WI.

McMaster, G.S., and W.W. Wilhelm. 1997. Growing degree-days: One equation, two interpretations. Agric. For. Meteorol. 87:291-300.

Meisinger, J.J. 1984. Evaluating plant available nitrogen in soil-crop systems. p. 391-416. In R.D. Hauck (ed.) Nitrogen in crop production. ASA, CSSA, and SSSA, Madison, WI.

Meisinger, J.J., F.R. Magdoff, and J.S. Schepers. 1992. Predicting N fertilizer needs for corn in humid regions: Underlying principles. p. 7-27. In B.R. Bock and K.R. Kelley (ed.) Predicting N needs for corn in humid regions. Bull. Y-226. TVA, Muscle Shoals, AL.

Miguez, F.E., and G.E. Bollero. 2006. Winter cover crops in Illinois: Evaluation of ecophysiological characteristics of corn. Crop Sci. 46:1536-1545.

Mulvaney, R.L., S.A. Khan, and T.R. Ellsworth. 2006. Need for a soilbased approach in managing nitrogen fertilizers for profitable corn production. Soil Sci. Soc. Am. J. 70:172-182.

Peterson, T.A., T.M. Blackmer, D.D. Francis, and J.S. Schepers. 1993. Using a chlorophyll meter to improve $\mathrm{N}$ management. Nebguide G93-1171A. Coop. Ext. Ser., Univ. of Nebraska, Lincoln.

Ritchie, S.W., J.J. Hanway, and G.O. Benson. 1986. How a corn plant develops. Iowa State Univ. Coop. Ext. Serv. Spec. Rep. 48.

SAS Institute. 2003. SAS/STAT user's guide. Release 9.1 ed. SAS Inst., Cary, NC.

Stanford, G. 1973. Rationale for optimum nitrogen fertilization in corn production. J. Environ. Qual. 2:159-166.

Stanford, G. 1982. Assessment of soil nitrogen availability. p. 651-688. In F.J. Stevenson (ed.) Nitrogen in agricultural soils. Agron. Monogr. 22. ASA, CSSA, and SSSA, Madison, WI.

Vanotti, M.B., and L.G. Bundy. 1994. An alternative rationale for corn nitrogen recommendations. J. Prod. Agric. 7:249-256.

Varvel, G.E., J.S. Schepers, and D.D. Francis. 1997a. Ability for inseason correction of nitrogen deficiency in corn using chlorophyll meters. Soil Sci. Soc. Am. J. 61:1233-1239.

Varvel, G.E., J.S. Schepers, and D.D. Francis. 1997b. Chlorophyll meter and stalk nitrate techniques as complementary indices for residual nitrogen. J. Prod. Agric. 10:147-151.

Varvel, G.E., and W.W. Wilhelm. 2003. Soybean nitrogen contribution to corn and sorghum in two-year cropping systems in the Western Corn Belt. Agron. J. 95:1220-1225. 